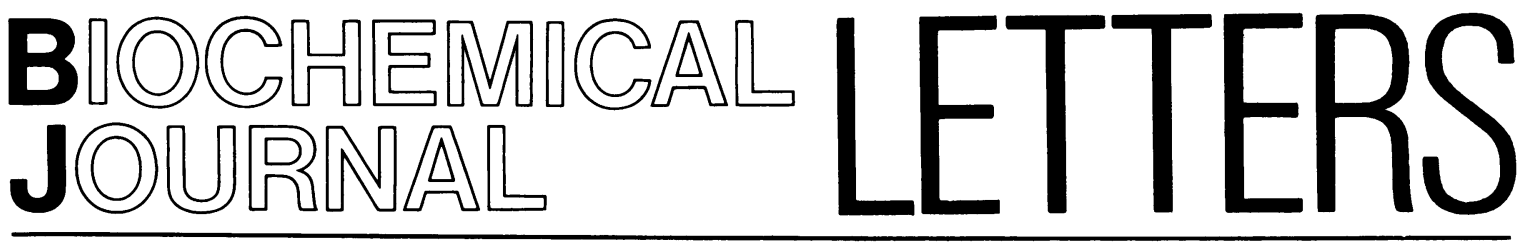

\section{Estimation of $K_{\mathrm{m}}$ values of enzymes requiring molecular $\mathrm{O}_{2}$ as a substrate}

I would like to raise a point in respect of biochemical usage and methodology, uncertainties about which have given rise to some confusion in the literature. It concerns the concentrations of $\mathrm{O}_{2}$ quoted in experiments on the kinetics of enzymes which have molecular $\mathrm{O}_{2}$ as one of their substrates. So far as I have been able to discover, there is no generally agreed convention about this. [The 'Instructions to Authors' issued by the Biochemical Journal, for instance, are silent upon the point, although recent examples (Brown \& Thomas, 1978; Greenwood et al., 1978) suggest that this journal is quite consistent in this matter.]

When kinetic studies are made with solid substrates which are dissolved in the reaction mixture, determining the exact concentrations usually poses no problem. In the case of a gaseous substrate, whose concentration is derived from a knowledge of the partial pressure of the gas in equilibrium with the liquid phase, a number of errors can arise in calculation. Some authors have avoided the difficulty by quoting $K_{\mathrm{m}}$ values for $\mathrm{O}_{2}$ in terms of the partial pressure of the gas in the gas phase either as a percentage or in $\mathrm{mmHg}$. Common sense and the need for easy comparability with other substrates suggest that the affinity of the enzyme for its substrate should be given in terms of the true concentration of the gas in contact with the enzyme, in molar units. Bachelard (1976a), in summarizing kinetic data concerning the $\mathrm{O}_{2}$-requiring processes in nervous tissue, has calculated molarities of the gas by means of a nomogram which allows the conversion of partial pressures to molarities (Bachelard, 1976b). Unfortunately, the molarities so derived refer only to the concentration of $\mathrm{O}_{2}$ in the gas phase, and not to that of dissolved gas. This results in quite wrong $K_{\mathrm{m}}$ values, which are especially misleading if they are quoted alongside figures which do refer to the true concentration of dissolved $\mathrm{O}_{2}$ (Bachelard, 1976a).

In calculating concentrations of a dissolved gas from a knowledge of its partial pressure, a considerable number of factors must be taken into consideration. They are the temperature, the at- mospheric pressure, the appropriate Bunsen absorption coefficient for the gas, the partial pressure of water vapour in the gas phase and the presence of solutes in the reaction mixture. (For examples of the last, see Chappell, 1964; Dixon \& Kleppe, 1965.) In addition the assumption is made that the $\mathrm{O}_{2}$ concentrations in the gas and liquid phases are at true equilibrium and that diffusion across the phase boundary is not rate-limiting. It is not always clear from the literature to what extent some of these factors have been considered. The last-named can only be determined empirically. By the use of standard tables (Documenta Geigy, 1970) one can calculate the concentration of $\mathrm{O}_{2}$ in pure water at $37^{\circ} \mathrm{C}$ in equilibrium with air at a pressure of $760 \mathrm{mmHg}(101325 \mathrm{~Pa})$. Table 1 shows some $K_{\mathrm{m}}$ values for enzymes recalculated on this basis.

The conditions of the calculation are very ideal, and omit consideration of the actual air pressure, which may be very much lower than $101325 \mathrm{~Pa}$. [See for instance Bublitz (1969), who carried out experiments at an altitude at which 1 atmosphere is equal to $628 \mathrm{mmHg}(83727 \mathrm{~Pa})$.] I have also totally disregarded the effect of solutes on the solubility of the $\mathrm{O}_{2}$. Chappell (1964) found that $1 \mathrm{M}-\mathrm{KCl}$ decreased the concentration of dissolved $\mathrm{O}_{2}$ by $27 \%$. Cumulatively, all the approximations involved in such estimates make the final $K_{\mathrm{m}}$ values rather inexact.

If an oxygen electrode is employed in the kinetic estimates (as is usually the case), these uncertainties

Table 1. $K_{m}$ values for $\mathrm{O}_{2}$

\begin{tabular}{|c|c|c|c|}
\hline & \multicolumn{2}{|c|}{$K_{\mathrm{m}}$ value for $\mathrm{O}_{2}$} & \\
\hline Enzyme & $\begin{array}{l}\text { Original } \\
\text { units }\end{array}$ & $\mathrm{mM}$ & Reference \\
\hline $\begin{array}{l}\text { Tyrosine } \\
\text { hydroxylase }\end{array}$ & $1 \%$ & 0.01 & $\begin{array}{l}\text { Fisher \& Kaufman } \\
\text { (1972) }\end{array}$ \\
\hline $\begin{array}{c}\text { Phenylalanine } \\
\text { hydroxylase }\end{array}$ & $0.35 \%$ & 0.0035 & $\begin{array}{l}\text { Fisher \& Kaufman } \\
\text { (1972) }\end{array}$ \\
\hline $\begin{array}{l}\text { Tryptophan } \\
\text { hydroxylase }\end{array}$ & $2.5 \%$ & 0.025 & Kaufman (1974) \\
\hline $\begin{array}{l}\text { Phenylalanine } \\
\text { hydroxylase }\end{array}$ & $194 \mathrm{mmHg}$ & 0.319 & Bublitz (1969) \\
\hline
\end{tabular}


are avoided and a true concentration of dissolved $\mathrm{O}_{2}$ may be found. Even so, care must be taken, as the oxygen electrode measures the activity of the dissolved $\mathrm{O}_{2}$ rather than its concentration. The true concentration of dissolved $\mathrm{O}_{2}$ may be determined empirically by, for instance, the method of Robinson \& Cooper (1970).

Quoting concentration of dissolved gases in terms of partial pressures is a legacy of the time when measurements of quantities of gases were made by volumetric means and were often related to transport in the blood stream. In this particular context where most of the $\mathrm{O}_{2}$, for instance, is not in solution, but is bound to haemoglobin, quoting $\mathrm{pO}_{2}$ values is still appropriate. I would like to suggest, however, that this is not true where kinetic measurements involving $\mathrm{O}_{2}$ as substrate of an enzyme are concerned. The availability of oxygen electrodes, and the uncertainties in converting from partial pressures to concentrations in solution, argue for the recording of $K_{\mathrm{m}}$ values for $\mathrm{O}_{2}$ in molar terms. Apart from any other consideration, this would remove from the literature a potential source of error in interpretation.

I should like to acknowledge advice and criticism from Professor H. S. Bachelard, Dr. C. Bublitz, Dr. C. A. Fewson, Dr. S. Kaufman and Dr. J. G. Lindsay.

\author{
Robin H. C. STRANG \\ Department of Biochemistry, \\ University of Glasgow, \\ Glasgow G12 8QQ, U.K.
}

\section{(Received 10 November 1980)}

Bachelard, H. S. (1976a) in Biochemistry and Neurological Disease (Davison, A. N., ed.), pp. 228-277, Blackwell, Oxford

Bachelard, H. S. (1976b) Clin. Sci. Mol. Med. 51, 203-204

Brown, S. B. \& Thomas, S. E. (1978) Biochem. J. 176, 327-336

Bublitz, C. (1969) Biochim. Biophys. Acta 191, 249-256

Chappell, J. B. (1964) Biochem. J. 90, 225-237

Dixon, M. \& Kleppe, K. (1965) Biochim. Biophys. Acta 96, 357-367

Documenta Geigy Scientific Tables (1970) (Diem, K. \& Lentner, C., eds.), 7th edn., J.R. Geigy SA, Basle

Fisher, D. B. \& Kaufman, S. (1972) J. Neurochem. 19, 1359-1365

Greenwood, C., Barber, D., Parr, S. R., Antonini, E., Brunori, M. \& Colisimo, A. (1978) Biochem. J. 173, 11-17

Kaufman, S. (1974) Ciba Found. Symp. 22, 85-108

Robinson, J. \& Cooper, J. M. (1970) Anal. Biochem. 33, 390-399

\section{The structure of acetyldihydro- lipoic acid}

Lipoic acid occurs covalently bound in amide linkage in the acyltransferase component of 2-oxo acid dehydrogenase multienzyme complexes (Reed, $1960,1974)$. In the course of action of these enzyme complexes the disulphide group of the lipoic acid is reductively acetylated and the acyl group is then transferred to coenzyme A. It is widely believed (e.g. Hageman, 1979) that the site of acylation of the enzyme-bound dihydrolipoyl group is its 6-mercapto group. This belief is based on the conclusion of Gunsalus et al. (1956) who found that exogenous dihydrolipoate could be acetylated by an extract of Escherichia coli. The methyl ester of this enzymically generated compound reacted smoothly with $N$-(diphenylmethylene)propionamide, which they thought suggested that it contained the primary $-\mathrm{CH}_{2} \mathrm{SH}$ group and so was the $\mathrm{S}^{6}$-acetyl compound. The chemically acetylated methyl dihydrolipoate did not react, so was assigned the $S^{8}$-acetyl structure.

O'Connor (1979; for some of his earlier findings see Paukstelis et al., 1977) used ${ }^{13} \mathrm{C}$ n.m.r. to examine the reaction product, and this study has cast doubt on the earlier view. He made $S$-[1$\left.{ }^{13} \mathrm{C}\right]$ acetyldihydrolipoamide from $\left[1{ }^{13} \mathrm{C}\right]$ acetyl-CoA both enzymically, by the same method as Gunsalus et al. (1956), and non-enzymically. The ${ }^{13} \mathrm{C}$ n.m.r. spectrum showed signals for both $S^{8}-\left(1-{ }^{13} \mathrm{C}\right)$ acetyldihydrolipoamide and $S^{6}-\left(1-{ }^{13} \mathrm{C}\right)$ acetyldihydrolipoamide in a ratio of about $2.5: 1$, indicating that both compounds were formed in both reactions.

It seems to us that transfer of acyl groups between the thiol groups of dihydrolipoamide in neutral aqueous solution may be quite fast. Such acyl transfer occurs readily from $S$ to $O$ in the series $\mathrm{CH}_{3} \mathrm{COS}\left[\mathrm{CH}_{2}\right]_{n} \mathrm{OH}$ when $n$ is 2 or 3 , but not when $n$ is 4 (Harding \& Owen, 1954; Martin \& Hedrick, 1962). The rate of transfer of acetyl groups between the primary and secondary groups of glycerol also rises with $\mathrm{pH}$ and is $0.056 \mathrm{~min}^{-1}$ at $\mathrm{pH} 7$ and $37^{\circ} \mathrm{C}$ (Wolfenden et al., 1964). Transfer between two thiol groups may be faster because of the greater nucleophilicity of such groups at neutral $\mathrm{pH}$, and may be slowed by the ring size of six instead of five in the intermediate, a decrease of 30 -fold for the $\mathbf{S} \rightarrow \mathbf{O}$ transfer studied by Martin \& Hedrick (1962).

The distribution of groups found by n.m.r. is therefore likely to represent equilibrium between $S^{6}$ and $S^{8}$-acetyl compounds. The ratio that may be inferred from signal strengths $(2.5: 1)$ is similar to that $(5.6: 1)$ measured by Wolfenden et al. (1964) for the distribution of acetyl groups between the primary and secondary hydroxyl groups of glycerol when correction is made for the presence in glycerol 